九州大学学術情報リポジトリ

Kyushu University Institutional Repository

\title{
Numerical Analysis of Crack Propagation in Beam Supported Reinforced Concrete Two-Way Slab
}

\section{Md. Ariful Hasan}

Dept. of Civil Engineering, European University of Bangladesh

Amin, Al

Dept. of Civil Engineering, European University of Bangladesh

Riyadul Hashem Riyad

Dept. of Civil Engineering, European University of Bangladesh

https://doi.org/10.5109/4738569

出版情報: Proceedings of International Exchange and Innovation Conference on Engineering \& Sciences (IEICES).7，pp.77-83，2021-10-21. 九州大学大学院総合理工学府 バージョン：

権利関係: 


\title{
Numerical Analysis of Crack Propagation in Beam Supported Reinforced Concrete Two-Way Slab
}

\author{
Md. Ariful Hasan ${ }^{1 *}$, Al Amin ${ }^{1}$, Riyadul Hashem Riyad ${ }^{1}$ \\ ${ }^{1}$ Dept. of Civil Engineering, European University of Bangladesh, Dhaka, Bangladesh. \\ *Corresponding author email: arifrainge@gmail.com
}

\begin{abstract}
In this study Finite Element Method (FEM) is used for analysis of crack propagation in a rectangular slab supported by peripheral beams. ANSYS Mechanical APDL 16.2 Software is used to carry out non-linear static analysis. SOLID65 solid element is used to model the continuum components. The Compressive crushing of concrete is simplified by consuming plasticity procedure, whereas the concrete cracking in tension region is found by the nonlinear physical model. The reinforcement is modeled by the smeared method and used because of the ratio of rebar implanted within the concrete slab to the whole volume of the concrete slab. The smeared reinforcement technique is more useful for the covered element such as a concrete slab. For this method it does not require explicit modeling of the rebar, For the analysis of slab much coarser mesh can be defined. The cracks appear at the top and bottom surface of the slab. The downward deflection that occurred at the underside of the slab. The spread of cracks within the slab established the system of yield line development. These results are compared with the theoretical results of yield line analysis. The cracking pattern of twoway slab that confirms the yield line analysis of slab.
\end{abstract}

Keywords: ANSYS, Reinforced concrete slab, smeared reinforcement, crack propagation

\section{INTRODUCTION}

In definition, slabs are structures that spread the load at right angles to their plane. Reinforced concrete slabs are broadly used as floors not only in residential and industrial buildings but also as decks in bridges. Twoway slabs are a form of construction exceptional to reinforced concrete, amongst the major structural materials. It is an economical, efficient, and widely used structural system. It is supported on all four sides and the length is less than twice the width [3]. The deflection of the two-way slab occurs in two directions, and the slab loads are transferred to all supports.

Generally, the reinforced concrete structures are designed based on experience or leading experimental research on real structures. While this technique needs a high amount of correctness, it is relentlessly very costly and time wasting. There are numerous approaches to modeling solid structures through mutually methodical and mathematical methods. Through the overview of advanced computers, Finite element analysis suited a standard device to investigate and design complex structures. The finite element method agrees with multifaceted investigation of the nonlinear response of reinforced concrete structures to be sanctioned out in indulgent its performance under the loading state. Finite element analysis offers an instrument able to simulate besides estimate the reactions of reinforced concrete members.

The accessibility of the quantity of the marketable finite element analysis codes, accompanied by the advanced parts for complex investigations. The use of the finite element analysis has enlarged due to developing Information and the ability of computer file plus hardware. Somewhat efforts on behalf of engineering evaluation can be done appropriately also recklessly by means of adaptable finite element enquiry sets likes ABAQUS, ANSYS mechanical APDL, ANSYS workbench, STRAND7 and others.

These nonlinear simulations perform a dynamic part in nonlinear reply investigates meanwhile individually substantial constituent inclines towards keep the complex stress-strain performance. Amongst these sets, ANSYS mechanical APDL offers a 3D component (SOLID 65) through a nonlinear model of the stiff ingredients like the concrete constituents. The component sorts a smeared crack equivalence intended for cracking in tension regions as well as a plasticity procedure on account of explaining the concrete devastating in compression regions.

Finite element method implies a mathematical investigation technique that splits the structural component into minor portions in addition to previously pretended fixed loading situations to calculate the retort of concrete as well as pre-stressed concrete members. This method is growing for the massive development of engineering besides computer information. This technique retorts well to the nonlinear investigation as each constituent holds dissimilar stress-strain performance.

Two methods exist for exhibiting reinforced concrete slabs: separate and layered modeling. Figure 3. 1 shows the separate display of the reinforced concrete slab. In the paper, concrete is displayed by way of 3D solid components though the rebar is exposed through truss components [13]. The relationship between a concrete $n$ node as well as the reinforcement steel node can be attained by two methods. At first technique, concrete as well as reinforcement coincide a similar point; henceforth perfect connection is expected. At second technique, the spring component is cast-off to attach concrete as well as reinforcement nodes. In spring toughness as well as bond slip connection could be employed to pretend the bond slip performance. Separate modeling of reinforced concrete slab provides additional accurate illustration of rebar than the covered method, which is a deliberated future. Though, it's extra luxurious in the investigation period, subsequently an enormous quantity of degree of freedom is mandatory. This remains of specific anxiety in nonlinear investigations. Moreover, the creation of this model is problematic as well as period consuming. Figure 3. 2 illustrates the layered method [5] for reinforced concrete slab. In that preparation, the fourth and nine node components are assumed. Concrete remains separated into a set of layers, though the rebar is grimy into a cover among concrete layers. Layered forming of reinforced concrete slabs is natural but 
proposes an unrealistic representation of the rebar. Meanwhile real reinforcement is separate, only extremely reinforced slabs can be properly modeled by the layered technique. In conclusion, in this technique, the grouping of the bond slip could only be extended preciously.

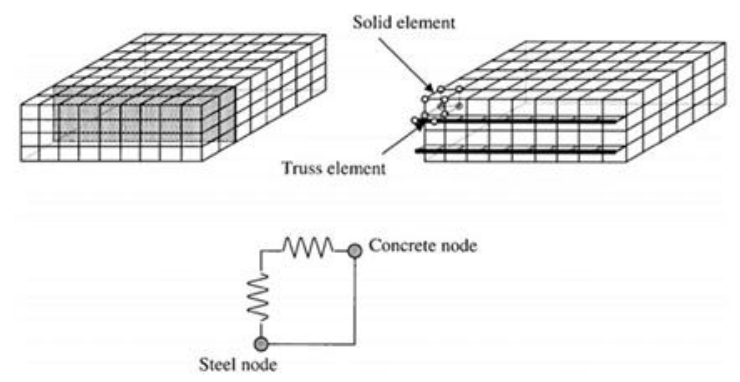

Fig 3. 1: Discrete modeling of reinforced concrete slabs.

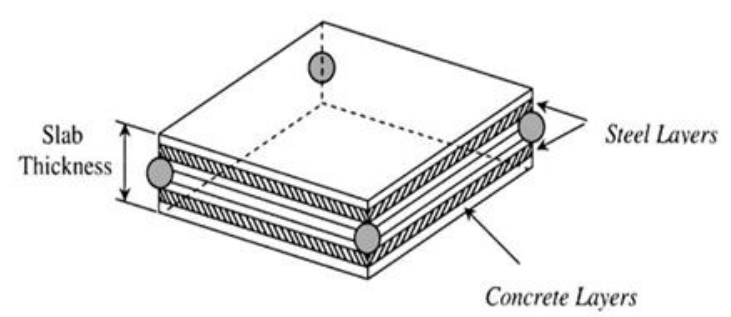

Fig 3. 2: Layered modeling of reinforced concrete slabs.

The finite component duplicates of $3 \mathrm{~m}$ normally reinforced concrete beams, created in ANSYS V16.2 utilizing the dedicated concrete components have exactly captured the nonlinear flexural rejoinder of these patterns up to failure. By means of finite component models to predict the strength of usual beams, the project of appropriate measurable resources is acute [14].

The ultimate load-carrying capacity of reinforced concrete flat slab exposed to uniform loading. The structure was evaluated by using a computer sequencer taking into explanation material non-linearity (for both concrete and reinforcement). Results designate that nonlinear properties in reinforced concrete slabs and most particularly skin action can result in effect floor load abilities more than the project values [15].

The effect of membrane action is uniformly loaded, isotropically reinforced concrete quadrangular slabs either motionless along two parallel edges with one edge simply supported beside one edge free [2].

The effect of membrane action is uniformly loaded reinforced concrete rectangular slabs having three fixed edges with one simply supported edge, two cases were examined on whether the simply supported edge of the slab is short or long [11].

The performance and competency of punching shear strength for flat slabs generated from rebar fiber protected self-compact concrete by solicitation nonlinear finite component system. Used component is proficient in plastic buckle, terribly in three orthogonal ways, besides devastating [8].

A three-dimensional finite component model to approve investigational trials known out on steel-concrete junctions. The nonlinear performance of this concrete is counterfeit, alongside with the situation condensed competency to repel large movements in firmness. The goal is to find the malleable performance of $\mathrm{RC}$ beam through a mathematical model in the system as found experimentally, the decrease of strength in post critical phase stays measured to pretend performance up to constructions distorted. The model through a destruction established model of concrete did not permit huge dislocations also occasioned in an unbalanced model that was not effective for the existing investigation [6].

The comportment of the examined concrete slabs had been experimental subjected to the crack pattern besides movement for numerous loading as well as boundary situations. The crack shape found by the ANSYS program has confirmed Johansen's theory that the location of suitable yield lines in a two-way reinforced concrete slab tracks the same pattern as the crack propagation [1].

The finite element technique for investigating the cracking outline of quadrilateral slabs by way of numerous edge situations. This failure approach is reached based on definite assumptions for example miscarriage is in line for the whole yielding of rebar beside the yield lines and yield lines arises on the tension surface, slab bends [9].

The dislodgement is extreme in slab consuming simple sustenance on all edges besides pressures are minimum in the equivalent slab sideways the boundaries. Likewise, slab through a fixed sustenance on all edges presented the minimum movement besides maximum pressures beside the boundaries of the slab [12].

The Cracking Identification in Reinforced Concrete Beams Utilizing ANSYS Software. The analysis of the linear area can be established on the design for flexure on behalf of a reinforced concrete beam. Assessments were done in that area to confirm refractions besides strains were steady through the finite element model in addition the beam beforehand crack happened. When cracking happens, bends besides pressures developed more problematic to forecast [14].

The wetter of plastic concrete is condensed by desertion, formwork immersion, besides oozing. Plastic shrinkage cracking seems on the surface of early age concrete afterward concreting besides while it is not still hard. These cracks appear frequently on horizontal surfaces. High evaporation rate, high water-cement ratio, and chemical response in cement paste cause plastic shrinkage in initial age concrete [10].

\subsection{OBJECTIVES}

$>$ Investigation of crack propagation in reinforced concrete two-way slab subjected to uniformly distributed load and supported by peripheral Beams.

\section{METHODOLOGY}

\subsection{The Idealization of Concrete}

The SOLID65 constituent models the nonlinear retort of reinforced concrete. The performance of material is founded on a constitutive typical for the tri-axial performance of concrete. SOLID65 is composed of plastic distortion as well as cracking in three directions respectively to the integration point. Cracking is modeled 
as a modification of the physical possessions that is done by varying the element stiffness matrix.

\subsection{Input data}

Table 1: The properties of Concrete before the surface of initial yield [4].

\begin{tabular}{|c|c|c|}
\hline Material name & $\begin{array}{c}\text { Modulus of } \\
\text { elasticity (MPa) }\end{array}$ & $\begin{array}{c}\text { Poison's } \\
\text { ratio }\end{array}$ \\
\hline Concrete & 29250 & 0.20 \\
\hline
\end{tabular}

Table 2: The parameters of Concrete past the surface of initial yield [4].

\begin{tabular}{|c|c|}
\hline $\begin{array}{c}\text { Transfer coefficient for } \\
\text { open shear, } \beta \boldsymbol{t}\end{array}$ & 0.30 \\
\hline $\begin{array}{c}\text { Transfer coefficient for } \\
\text { closed shear, } \beta \boldsymbol{c}\end{array}$ & 0.90 \\
\hline $\begin{array}{c}\text { The stress of uniaxial } \\
\text { cracking }\end{array}$ & $1.5 \mathrm{MPa}$ \\
\hline $\begin{array}{c}\text { The stress of uniaxial } \\
\text { crushing }\end{array}$ & $25 \mathrm{MPa}$ \\
\hline
\end{tabular}

\subsection{Stress vs Strain Relationship of Concrete}

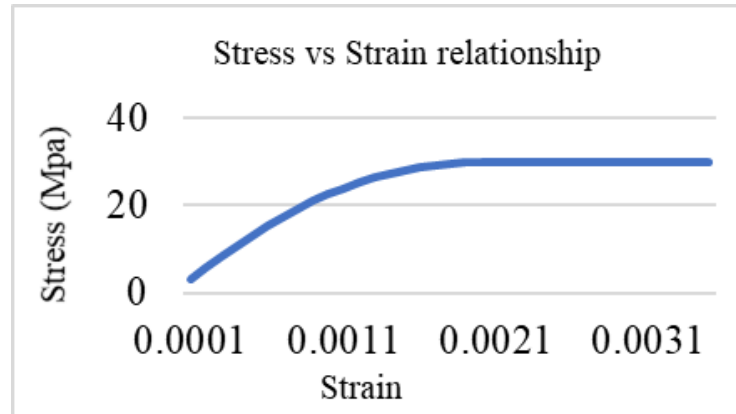

Fig 4. 1: Stress vs Strain relationship

\subsection{Physical modeling}

For the modeling SOLID65 element is used. The size of the concrete block is $2 \times 3 \mathrm{~m}$ and thickness is $200 \mathrm{~mm}$. The cover of Concrete is $25 \mathrm{~mm}$ used, besides rebar implemented is the diameter bar $8 \mathrm{~mm} @ 250 \mathrm{~mm} \mathrm{c} / \mathrm{c}$ as shown in Figure 4. 2.

Two real constant sets for the SOLID65 element are formed. The first one does not have a volume ratio (the volume ratio is demarcated as the rebar volume divided by the total element volume) for the reinforcement, the second one does. Then, two separate volumes adjacent to each other and one under the other are created (Fig. 4. 2). The glue operation used by ANSYS redefines the input volumes so that they share areas besides their common boundaries. Before meshing, choose the first real constant set for the upper one besides the second set for the other as mesh attributes (Fig. 4. 3). For the meshing select the smart size coarser mesh.

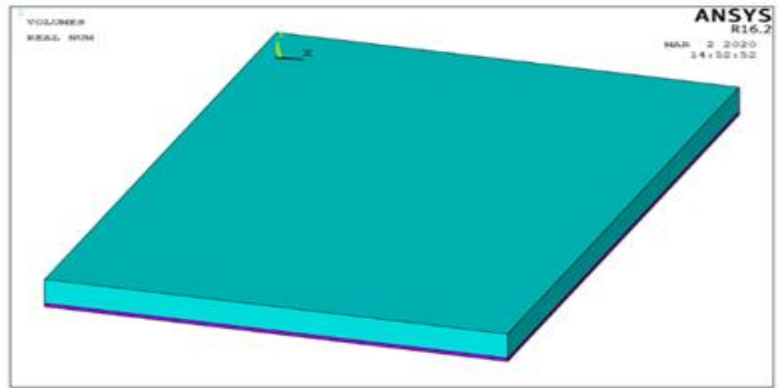

Fig 4. 2: Physical model of two-way slab

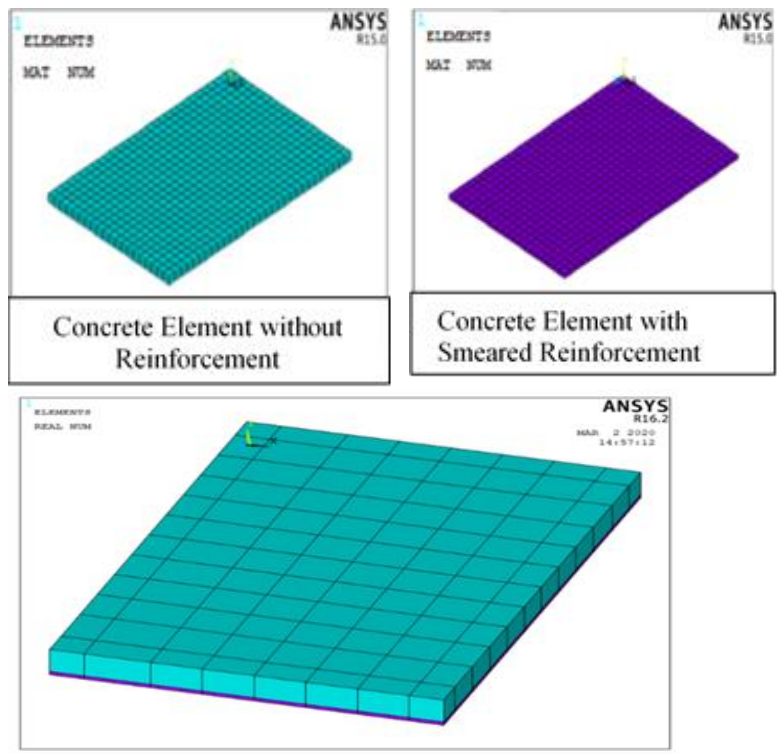

Fig 4. 3: Finite Element Model

\subsection{Apply Boundary Condition}

An object has six degrees of freedom in space. There are three translational and three rotational degrees of freedom.

In ANSYS, for Fixed Support, we restrict all the DOF at edge. For applying boundary conditions, select the face of all sides, then apply all degree of freedom. Displacement value $=0$. Shown in figure 4. 4 .

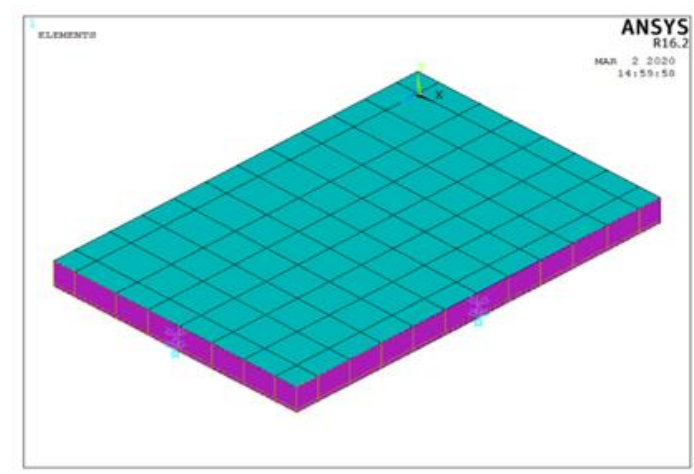

Fig 4. 4 : Boundary Condition 


\subsection{Apply load}

For the applying load, select all nodes of the top surface and then apply $12 \mathrm{KN} / \mathrm{m}^{2}$ load. Shown in Figure 4. 5 .

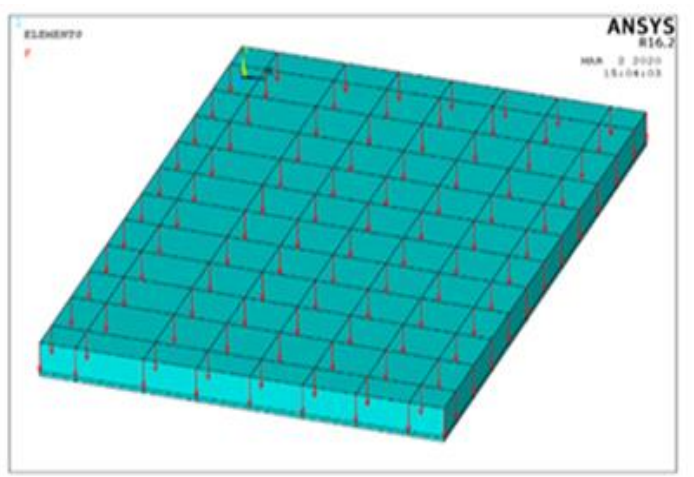

Fig 4. 5: Loading condition

\subsection{Solution}

$>$ Select solution option

$>$ Then go to the analysis type.

$>$ Select solution control.

D Analysis option- small-displacement static.

$>$ Then select the time at the end of the load step.

$>$ Automatic time stepping - program chosen.

$>$ Chose the number of sub steps, the maximum number of sub steps, minimum number of sub steps.

$>$ Select frequency, Write every Nth sub step, where $\mathrm{N}=1$.

$>$ The iteration of newton-raphson deliver the convergence for every load raise within given aceptable limit.

$>$ Select equation solver sparse direct.

$>$ Then chose the maximum number of iteration.

$>$ Then select the nonlinear convergence criteria. If the load will heavily increase then the solution is not converged.so care about it.

$>$ Then click the current load step file.

\section{RESULTS AND DISCUSSIONS}

The sequential failure patterns that were observed in a rectangular slab supported by peripheral beams are shown in Fig 5. 1 to Fig 5. 8.

In fig 5.1 the acting of load on the slab is $4.72 \mathrm{KN} / \mathrm{m}^{2}$. Up to this loading, the slab performs elastically. The bend is minor as well as up to that point, it follows the Hooke's law.

In figure 5. 2, Beyond the loading $4.72 \mathrm{KN} / \mathrm{m}^{2}$ first crack occurs at the edge of the slab due to negative bending moment. At loading $5.04 \mathrm{KN} / \mathrm{m}^{2}$ cracks are appeared in top and bottom face of the slab. Shown in figure 5. 3 .

At loading $6.32 \mathrm{KN} / \mathrm{m}^{2}$ flexural cracks spread from mid span to support. Shown in figure 5. 4.

Diagonal Cracks appear at loading $7.84 \mathrm{KN} / \mathrm{m}^{2}$ that is shown in figure 5. 5. When the applied loads is increased, it induced extra diagonal as well as flexural cracks. Shown in figure 5. 6 to figure 5.9.

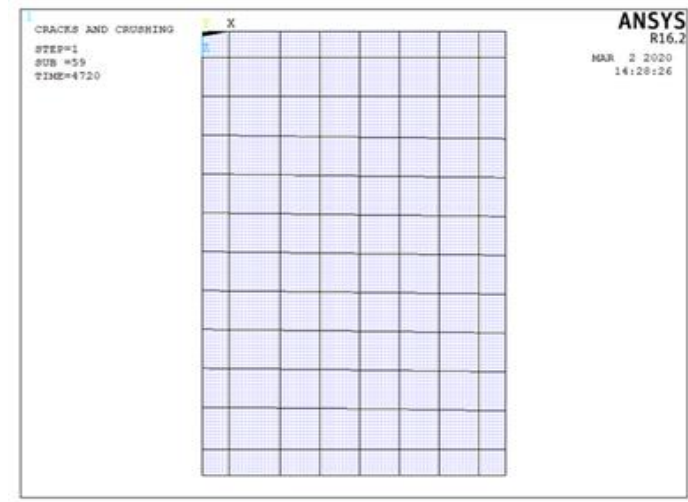

Fig 5. 1: No cracks

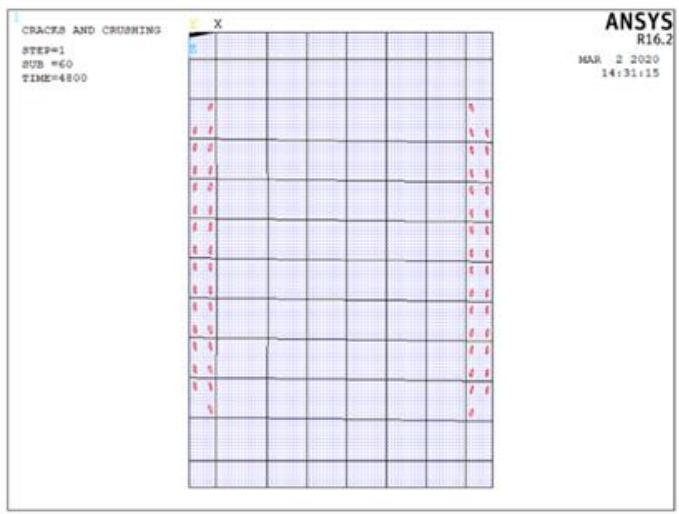

Fig 5. 2: First cracking at top face

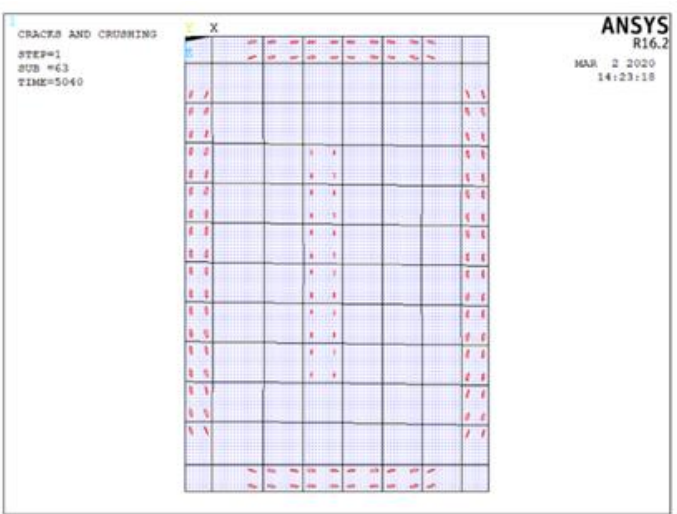

Fig 5. 3: Further Cracking ( top and bottom face)

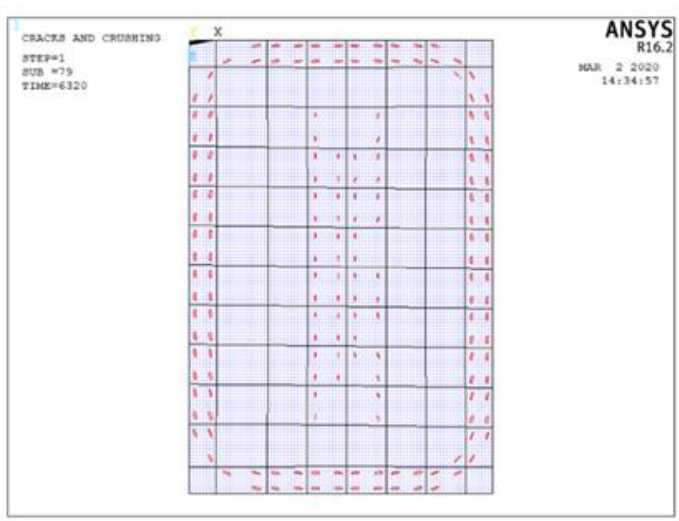

Fig 5. 4: Further cracking ( top and bottom face) 


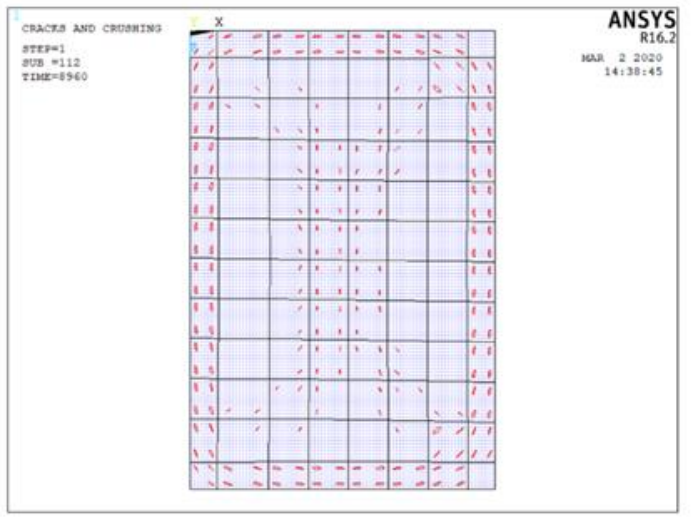

Fig 5. 5: The cracking of diagonal

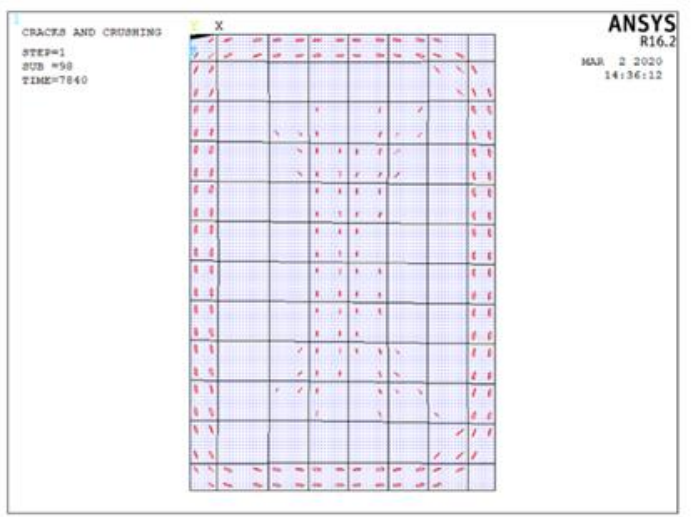

Fig 5. 6: Further cracking

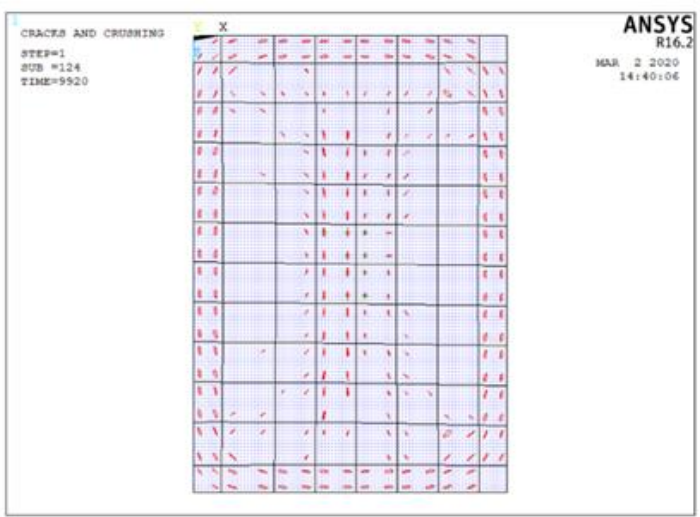

Fig 5. 7: More crack formation

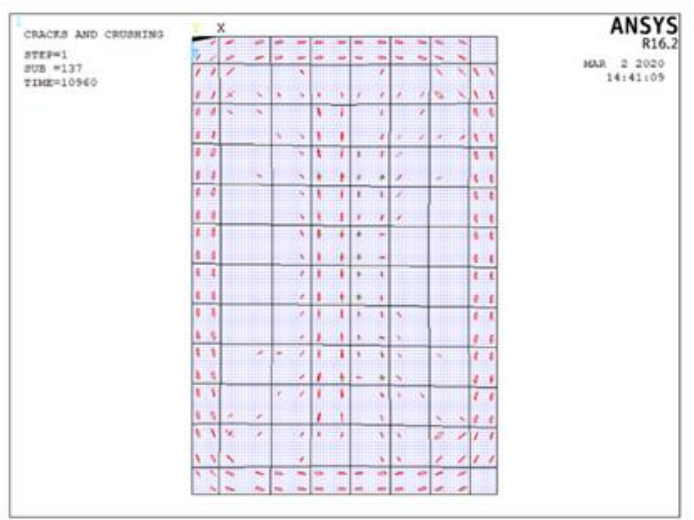

Fig 5. 8: More crack formation

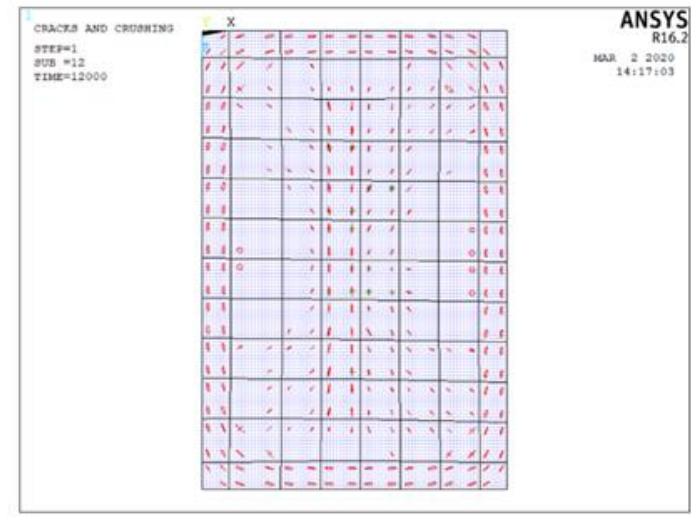

Fig 5. 9: cracking at failure

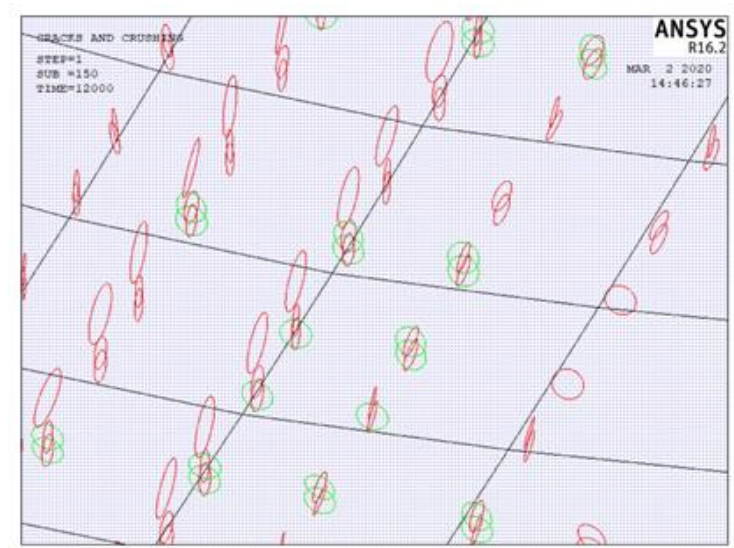

Fig 5. 10: Cracking of reinforced concrete
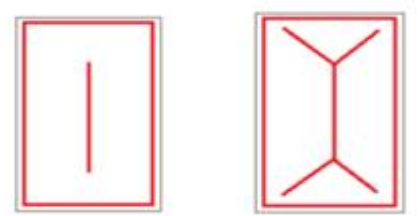

(a) First yielding

(b) Further development of yield lines

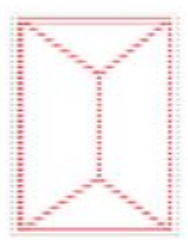

(c) Collapse mechanics formed

Fig 5. 11: Yield line pattern for a fixed slab [7] [9].

The crack formation in the slab starts to develop after one set of yielding of the reinforcements. The yield line pattern caused by the crack formation reaches its maximum length at failure. Overall, the flexural cracks arise premature at mid-span. While applied loads rise, vertical flexural cracks extend parallel from mid span to support. When a greater load is applied, the diagonal tensile cracks perform. In conclusion, the appearance of compressive cracks at the last steps of loads. The integration point cracking and crushing of the concrete in ANSYS program are represented by circles and octahedron outlines respectively with different colors. A red outline for the first crack, a green outline for the second crack and the blue outline for the third crack 
(Figure 5. 10) and The slab extents it's the load of ultimate collapse in between $10-12 \mathrm{KN} / \mathrm{m}^{2}$ as well as the oblique deflection quickly rises by way of the load step rises from $10 \mathrm{KN} / \mathrm{m}^{2}$ to $12 \mathrm{KN} / \mathrm{m}^{2}$. The collapse of slab could also be established by the study of cracking patterns.

The downward deflection that occurred at the bottom of the slab is shown in figure 5.12 and the cracks appearing top and bottom surface of the slab are shown in figure 5 . 13

In figure 5. 14 shows the Load-Deflection relationship.

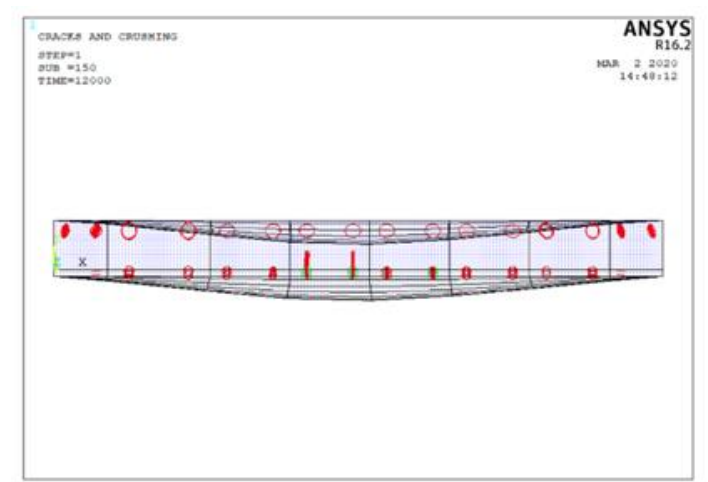

Fig 5. 13: Cracks and deflection

When the load increases, the deflection also increases and the load-deflection line is not linear.

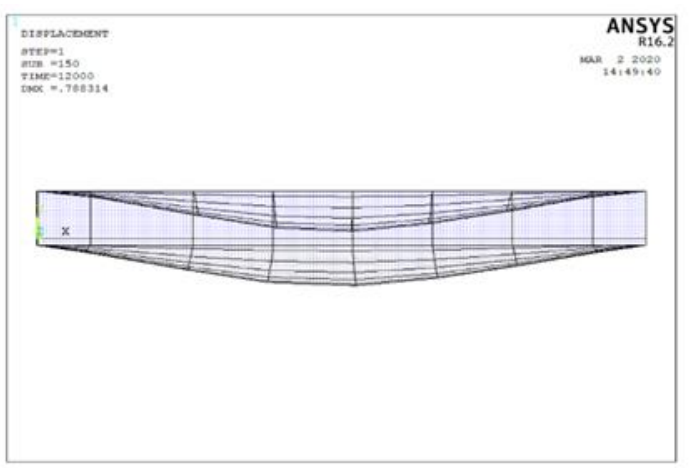

Fig 5. 12: Deflection of slab

Table 3: Load- Deflection value

\begin{tabular}{|c|c|}
\hline Load $\left(\mathrm{KN} / \mathrm{m}^{2}\right)$ & Deflection $(\mathrm{mm})$ \\
\hline 1 & 0.0265 \\
\hline 2 & 0.0531 \\
\hline 3 & 0.0796 \\
\hline 4 & 0.10616 \\
\hline 5 & 0.24479 \\
\hline 6 & 0.32826 \\
\hline 7 & 0.39076 \\
\hline 8 & 0.45131 \\
\hline 9 & 0.51291 \\
\hline 10 & 0.64447 \\
\hline 11 & 0.71544 \\
\hline 12 & 0.78357 \\
\hline
\end{tabular}

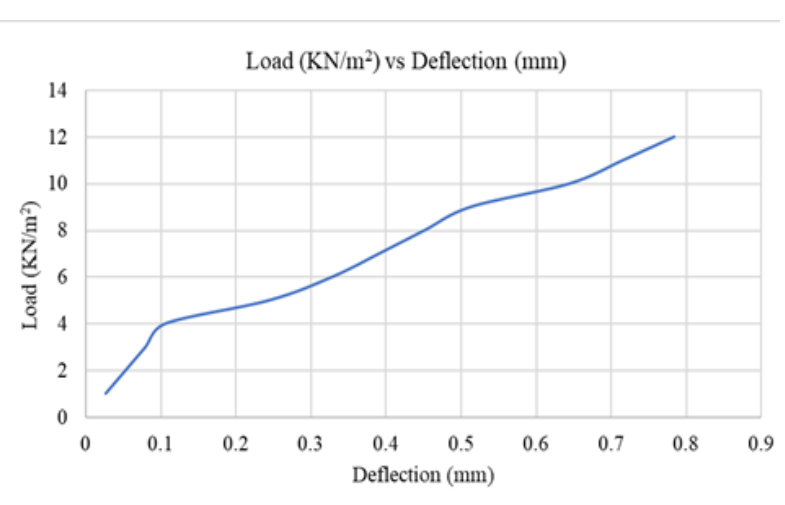

Fig 5. 14: Load vs Deflection relationship

\section{CONCLUSIONS}

Finite element model of $3 \times 2 \mathrm{~m}$ typically reinforced concrete slab, is developed using commercial generalpurpose finite element analysis program ANSYS16.2.

The captured of nonlinear flexural response of concrete slab towards failure

The following decisions could be stated established on the valuation of the investigates of the RC slab:

$>$ The propagation of cracks in the slab (Fig.5. 8 and 5.9) inveterate the formation of yield line sequence [7], [9] by way of the load being enlarged up to the load of collapse.

$>$ The cracks appear at top and bottom surface and the downward deflection that occurred at the bottom of the slab. Shown in Fig 5.12 and 5.13.

The model of failure concrete [16] agreed to the code of ANSYS with the smeared reinforcement approach is suitable to determine the nonlinear behavior of reinforced concrete structures. Using Finite Element Modeling permits us to predict the results of experimental work before starting, which leads to minimize the cost of laboratory work.

\section{RECOMMENDATIONS}

$>$ Further studies will be needed to verify the behavior of two-way slabs under Impact loading condition.

$>$ The study will be conducted to analyze the slab by use of shall element.

$>$ Further studies will be needed to analyze the behavior of slabs by the use of SOLID65 element with discrete reinforcement modeling.

$>$ Moreover, the study will be conducted to analyze the two way reinforced concrete slabs with also without opening consuming different limit conditions.

\section{REFERENCES}

[1] A. Gherbi, L. D. Study on Two Way Reinforced Concrete Slab Using ANSYS with Different Boundary Conditions and Loading. International Journal of Civil and Environmental Engineering, (2018) 1151-1156.

[2] Al-Shimmery, Membrane Action in R.C. Rectangular Slabs Having One Free. Baghdad: M.Sc. Thesis, University of Technology (June, 2005).

[3] Daham, H. A. Analytical study of reinforced concrete twoway slabs with and without opening having (2011).

[4] DrDalyo. ANSYS reinforced concrete beam static structural (2015). 
[5] Hand, F. R. "Nonlinear layered analysis of RC plates and shells". J. Struct. Div. ASCE (1973) 1491-1505.

[6] Isaac Montava, R. I. Numerical Simulation of Steel Reinforced Concrete (26 January 2019).

[7] Johansen, K. Yield Line Theory. London, UK: Cement and Concrete Association(1962).

[8] Ragab, K. S. Study Punching Shear of Steel Fiber Reinforced Self Compacting Concrete Slabs by Nonlinear Analysis. International Journal of Civil and Environmental Engineering (2013) 624-635.

[9] Rajesh Kumar, V. K. Yield Line Analysis of Rectangular Slabs by Finite Element Method. Proc. of the Second Intl. Conf. on Advances In Civil, Structural and Environmental Engineering- ACSEE (2014) (pp. 113-117).

[10] Razavi S.V, M. H. A new approach to analysis plastic shrinkage cracks in reinforced concrete slabs by using ann. Journal of Petroleum and Gas Exploration Research (December, 2011) 65-71.

[11] Salman. Membrane Action in Orthotropically Reinforced Concrete Rectangular Slabs Restrained on Three Edges Only. Baghdad: M.Sc. Thesis, University of Technology (May, 2006).

[12] Sheetal Gawas, D. S. Study on Two way RC Slab using ANSYS with and without central opening. International Journal of Scientific Engineering and Technology (2014 )1108-1110.

[13] Sotelino, K. P. Nonlinear Finite Element for Reinforced Concrete Slabs. J. Struct. Div. ASCE (2005). 643-649.

[14] T. Subramani, R. M. Crack Identification in Reinforced Concrete Beams Using Ansys. Int. Journal of Engineering Research and Applications (June, 2014) 133-141.

[15] Vecchio, F. a. Investigation the Collapse of a Warehouse"(1990) Vol.12, no.3, 72-78.

[16] Amin, A., Islam, M., \& Ahamed, M. J. Base isolation of multi-storied building using lead rubber bearing. ITEGAM-JETIA (2020) 6(26), 52-60.

[17] Warnke, K. J. "Constitutive model for the triaxial behavior of concrete,". Proc. of the Int. Association for Bridge and Structural Engineering, ISMES (1975).

[18] Arakawa, K. Effect of time derivative of contact area on dynamic friction (2015).

[19] Rushdi, M., Yoshida, S., \& Dief, T. N. Simulation of a Tether of a Kite Power System Using a Lumped Mass Model (2018). 